\title{
Development and prospect on fully mechanized mining in Chinese coal mines
}

\author{
Jinhua Wang
}

Received: 15 October 2013/Revised: 20 December 2013/Accepted: 22 December 2013/Published online: 10 October 2014

(C) The Author(s) 2014. This article is published with open access at Springerlink.com

\begin{abstract}
Fully mechanized mining (FMM) technology has been applied in Chinese coal mines for more than 40 years. At present, the output of a FMM face has reached 10-million tons with Chinese-made equipment. In this study, the new developments in FMM technology and equipment in Chinese coal mines during past decades are introduced. The automatic FMM technology for thin seams, complete sets of FMM technology with ultra large shear height of $7 \mathrm{~m}$ for thick seams, complete sets of fully mechanized top coal caving technology with large shear height for ultra-thick seams of $20 \mathrm{~m}$, complete sets of FMM technology for complex and difficult seams, including steeply inclined seams, soft coal seams with large inclination angle, and the mechanized filling mining technology and equipment are presented. Some typical case studies are also introduced. Finally, the existing problems with the FMM technology are discussed, and prospect of FMM technology and equipment applied in Chinese coal mines is put forward.
\end{abstract}

Keywords Fully mechanized mining · Mining with large shear height · Fully mechanized top coal caving ·

Steeply inclined seam $\cdot$ Backfilling mining $\cdot$ Prospect

\section{Current coal productivity in China}

According to data from the BP Statistical Review of World Energy 2013 program, global coal output in 2012 was 7,864 million tons, of which 3,660 million tons were produced by China. Coal accounted for $76.6 \%$ and $67.1 \%$ of China's primary energy production and consumption structure, respectively, and $47.5 \%$ and $50.2 \%$ of the world coal production and consumption, respectively. Globally, China leads in both coal output and consumption. By 2020, China's coal output is expected to reach 3,800 million tons, of which at least $55 \%$ will be used for primary energy consumption.

Since 2000, China has been updating long-effective production safety mechanisms implemented in its coal mines, while also improving on its fully mechanized

J. Wang $(\bowtie)$

China Coal Technology \& Engineering Group Corp.,

Beijing 100013, China

e-mail: e-mtxb@163.com mining (FMM) technology and equipment. These advancements have led to the development and successful implementation of complete sets of automatic FMM technology used for $0.6-1.3 \mathrm{~m}$ thin seams, complete sets of FMM technology with $7 \mathrm{~m}$ ultra-large shear height for thick seams, complete sets of fully mechanized top coal caving technology with large shear height for $20 \mathrm{~m}$ ultrathick seams, and complete sets of FMM technology for seams with large dip angle of $35^{\circ}-55^{\circ}$. Such advanced mining technologies have provided technical support for safe, efficient, and sustainable development in Chinese coal industry. A large number of safe and efficient coal mines with 10-million-ton capacity have emerged in Chinafrom only one in 2001 to 53 in 2013-whereas output soared from 11 to 730 million tons, accounting for $19.8 \%$ of the Chinese total coal output. The overall economic technical index of coal mines with 10 million tons capacity has reached the international leading level, and a number of world records have been broken in terms of the output of a coal face, working efficiency, and fully mechanized roadway advance rate. 


\section{FMM technology and equipment for thin seams}

Coal mined from thin seams with thicknesses of $1.3 \mathrm{~m}$ or less accounts for approximately $20 \%$ of Chinese total coal reserve. Thin seams occur in more than $85 \%$ of the Chinese coal mines. Safe and efficient methods for the mining of thin seams have historically presented technical challenges for the coal industry. Confined spaces, substandard working conditions, high labor intensity, high heading rate, and complex field management have hampered improvements in thin-seam mining technology. These limitations have resulted in a lack of mechanization, low standards in work efficiency, high safety risk, and poor economic performance (Mao et al. 2011; Ning 2013).

From 2006 to 2010, the MG100/238-WD conveyormounted, electric haulage drum shearer was successfully implemented with a total installation capacity of $238 \mathrm{~kW}$ and applicability to coal seams of thicknesses $0.8-1.25 \mathrm{~m}$. This event marked the breakthrough of the $1.0 \mathrm{~m}$ limitation for Chinese FMM technology and created a new domestic benchmark in the nation's FMM technique and equipment used to mine thin seams (Wang 2009).

Recent mining practices on thin seams in some coal mines have indicated that for minor cutting heights, equipment that is scientifically designed, packaged, and fully mechanized can also achieve satisfactory technicaleconomic performance. Currently, thin seams with thicknesses of approximate $1 \mathrm{~m}$ can yield a productivity of about $1 \mathrm{Mt} /$ year if suitable equipment is used.

As a solution to the challenges faced by FMM for steeply inclined thin seams with angles of $60^{\circ}$ or greater mines in Yunnan and Guizhou Provinces, such as inaccessibility and equipment turnover and slip, China Coal Technology \& Engineering Group Corp. (Fan 2012) has developed a steeply inclined, thin-seam strike longwall FMM approach and all designed related mining equipment to support this approach. The group has successfully developed a JBB-I steeply inclined, thin seam, conveying FMM unit that enables the automatic mining of $0.7-1.5 \mathrm{~m}$ steeply inclined thin seams with maximum dip angles of $70^{\circ}$. This unit consists of a plough chain that drives a number of small heads to run in a cycle along the beam to cut coal simultaneously from various points with scattered acting force and balanced mechanical operation. The entire unit is electro-hydraulically controlled, allowing for unmanned production within the work face. In the second half of 2013, the first unit underwent industrial testing in the Taiping coal mine of the Panzhihua coal mining district, Sichuan Province. This conveying FMM unit exhibited high potential for more extensive application to the aforementioned complex seams and is expected to improve the mechanized mining capability in minor coal mines.

\section{FMM technology and equipment for medium-thick seams}

FMM technology for medium-thick seam with thicknesses of $1.3-3.5 \mathrm{~m}$ is widely used both in China and abroad. When suitable FMM equipment is used, maximum productivity can exceed $5 \mathrm{Mt} / \mathrm{year}$. In the case of the Yujialiang mine, the Shendong coal mining district, the coal seam No. 4-2 with the average thickness of $3.64 \mathrm{~m}$ was mined. The length of working face 44208 of this mine was $400.5 \mathrm{~m}$, which made it the longest FMM face in China. With a cutting rate of 70-80 min per cut and 14 cuts per day, a recovery efficiency of $506 \mathrm{t} /$ power and an annual output of 8.2 million tons were obtained, and this working face was an example of safe and efficient mining of medium-thick seams and represented the best domestic capability of FMM of medium-thick seams.

\section{FMM mining technology and equipment with large shear height for thick seams}

The recoverable reserve of thick seams in China accounts for approximate $43 \%$ of the nation's total recoverable coal reserve. The annual output from thick-seams accounts for $40 \%-50 \%$ of the nation's total output. Hence, safe and efficient mining technology for thick-seams will have a significant impact on the future of Chinese coal industry.

In a number of new large coal mines in Shanxi, Shannxi, and Inner Mongolia, the main seams are subhorizontal with a thickness of 6-7 m. Although these seams have a stable occurrence, they are hard and unsuitable for top coal caving. How to extract these thick seams with high efficiency, safety and high recovery rates using the FMM technology with large shear height has become an important topic for the coal mines. After nearly 10 years of practices and research, substantial progress has been made with respect to strata control theory, equipment research and development, safety security procedures associated with the FMM technology with large shear height. The complete sets of the FMM technology with large shear height have been independently developed and successfully used for seams with thickness of 3.5-7.0 m. The difficult issues associated with spalling, roof collapse, and support stability control in work face with large shear height have been solved. Especially for powered hydraulic supports, the high strength, welded structural steel used for hydraulic supports, and steel-welding technology for high strength steel with complex structures in hydraulic supports were developed, and the service life of hydraulic supports was improved to 80,000 cycles, which secured the stability and reliability of the supporting system for the work face with large shear height of $7 \mathrm{~m}$. 


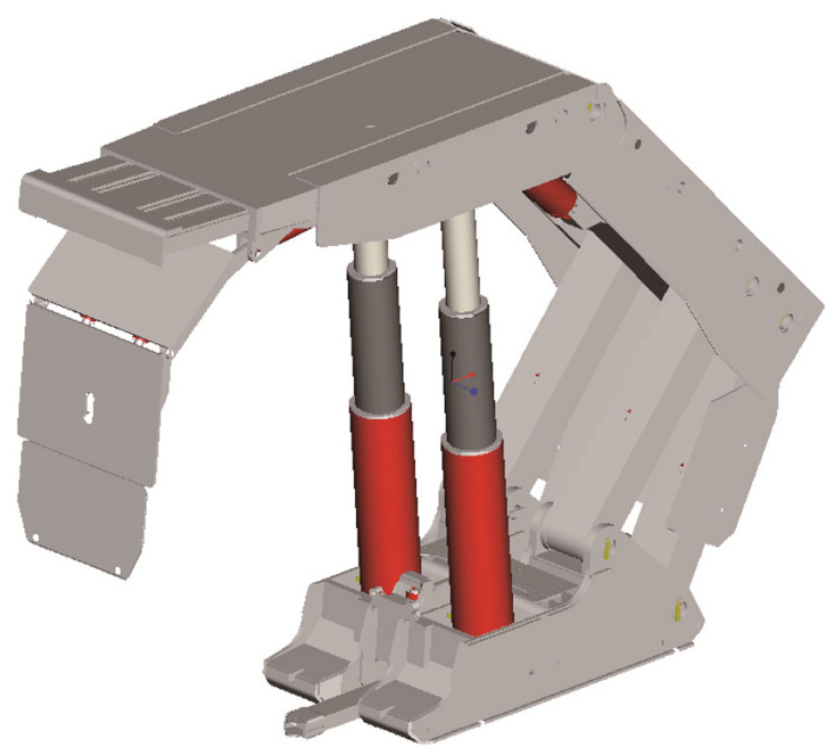

Fig. 1 Hydraulic support ZY18800/32/72D with large shear height

Table 1 Parameters of the ZY18800/32/72D hydraulic support

\begin{tabular}{ll}
\hline Support height $(\mathrm{mm})$ & $3,200-7,200$ \\
Support width $(\mathrm{mm})$ & $1,960-2,210$ \\
Support distance between centers $(\mathrm{mm})$ & 2,050 \\
Support intensity $(\mathrm{MPa})$ & $1.60 / 1.47$ \\
Specific pressure at floor tip end $(\mathrm{MPa})$ & $2.6-5.6$ \\
Setting force $(\mathrm{kN})$ & 12,364 \\
Working resistance $(P=47.8 / 43.3 \mathrm{MPa})$ & $18,800 / 17,000$ \\
$\quad(\mathrm{kN})$ & \\
Operation mode & Electro-hydraulic \\
& control \\
Weight (tons) & 69.79 \\
\hline
\end{tabular}

\subsection{FMM mining technology with $7 \mathrm{~m}$ ultra-large} shear height for thick seams

From 2006 to 2010, the MG1000/2500-WD electric haulage shearer was implemented, the complete sets of whole Chinese-made work face equipment were formed, and a demonstration work face with an expect output of $10 \mathrm{Mt} /$ year in the Xiegou mine of the Xishan coal mining district was set. During the industrial test, a maximum daily output of $36 \mathrm{kt}$ and maximum monthly output of $876 \mathrm{kt}$ were recorded, which nearly achieved the expect output of $10 \mathrm{Mt} /$ year (Wang 2011; Ning 2012).

The FMM face 15205 with large shear height in the Hongliulin Mine, Shannxi Coal \& Chemical Industry Group, was equipped with hydraulic supports ZY18800/32/ $72 \mathrm{D}$ as shown in Fig. 1. Its parameters are shown on Table 1. Large-capacity scraper conveyors SGZ1400/4500 and other associated equipment were employed. The remote control technology was applied for real-time control of the FMM equipment. This work face was the first typical underground example of using a packaged intelligent system on the FMM face with the largest installed power system, highest shear height, intelligence level, and output. Its intelligent control functions include a central gateway control for the FMM equipment and remote one-key start-and-stop function from the ground level. The number of operators on the work face was reduced to $3-5$, signaling the move to a reduced-manpower shift or unmanned safe and efficient production in a coal mine.

Thus far, the FMM technology and equipment with 7-m ultra-large shear height for thick seams have been successfully used in a number of mines, including Bulianta, Sandaogou mine of Shenhua and Hongliulin mine, and an annual production capacity of more than 10 million tons per work face was reached, marking technical breakthroughs as well as the safe and efficient production of the FMM faces with large shear height (Wang 2005, 2006; Ning 2011). Typical application examples of the FMM faces with large shear height in Chinese coal mines are shown on Table 2.

\subsection{FMM mining technology with large shear height for steeply inclined seams}

Safe and efficient mining of steeply inclined seams is challenged by the factors such as inherent instability of equipment on the working face, roof failure, equipment slip, difficulty on haulage brake, wear-prone and shortlived key load-bearing elements, and poor equipment matching performance as a result of large dip angles. To resolve the global technical problems in stability control of the FMM equipment used in seams with large dip angle, China Coal Technology \& Engineering Group Corp. invented hydraulic supports suitable to seams with large dip angle on the basis of many years of research and development, creatively established supporting systems for the FMM/full mechanized top coal caving faces with large dip angles, and solved the key technical problems associated with anti-toppling equipment and stability control of hydraulic supports used in seams with large dip angles of $35^{\circ}-55^{\circ}$. Moreover, the company developed a coupling mechanical model for hydraulic supports used in seams with large dip angles and surrounding rock, provided stability control strategy for hydraulic supports used in seams with large dip angles, and creatively developed a "selfsupport, adjacent support pulling, bottom pushing, top extrusion" antitoppling and antislip mechanism coupling hardness with softness and a three-dimensional (3D) protective device for hydraulic supports. These hydraulic supports were applied in the seam with a large dip angle of $55^{\circ}$ in the Fucheng coal mine of Inner Mongolia, a daily 
Table 2 Parameters and equipment of the FMM faces with large shear height for thick seams in China

\begin{tabular}{|c|c|c|c|c|}
\hline $\begin{array}{l}\text { Coal mining } \\
\text { district }\end{array}$ & Coal mine & $\begin{array}{l}\text { Key equipment used } \\
\text { for working face }\end{array}$ & Equipment configuration & $\begin{array}{l}\text { Parameters of } \\
\text { face output }\end{array}$ \\
\hline \multirow[t]{6}{*}{ Shendong } & Daliuta & ZY8640/24/50D & All are imported except the supports & $240,5,004 \mathrm{~m}, 780 \mathrm{kt} / \mathrm{m}$ \\
\hline & Huojitu & ZY12000/25/50D & All are imported except the supports & $257,3,000 \mathrm{~m}, 580 \mathrm{kt} / \mathrm{m}$ \\
\hline & Bulianta, Shangwan & $\begin{array}{l}\text { ZY10800/28/63D } \\
\text { ZY16800/32/70D }\end{array}$ & All are imported except the supports & $320,3,000 \mathrm{~m}, 930 \mathrm{kt} / \mathrm{m}$ \\
\hline & Wanli No.1 mine & ZY8600/24/50D & All Chinese-made except pumping station & - \\
\hline & Nalinmiao No.1 mine & ZY13000/28/63D & All Chinese-made & $180,3000 \mathrm{~m}, 630 \mathrm{kt} / \mathrm{m}$ \\
\hline & Nalinmaio No.2 mine & ZY8600/25.5/55D & All Chinese-made & $200,2,200 \mathrm{~m}, 600 \mathrm{kt} / \mathrm{m}$ \\
\hline \multirow[t]{2}{*}{ Qinshui } & Sihe & $\begin{array}{l}\text { DBT255/550-8640 } \\
\text { ZY8640/25.5/5.5 } \\
\text { ZY9400/28/62 } \\
\text { ZY12000/28/62 }\end{array}$ & $\begin{array}{l}\text { Shearers, scrapper conveyors, transfer conveyors } \\
\text { and crushers are imported }\end{array}$ & $300,3,000 \mathrm{~m}, 660 \mathrm{kt} / \mathrm{m}$ \\
\hline & Zhaozhuang & $\begin{array}{l}\text { ZY8640/25.5/55 } \\
\text { ZY12000/28/62 }\end{array}$ & Shearers and conveyors are imported & $220,1,500 \mathrm{~m}, 400 \mathrm{kt} / \mathrm{m}$ \\
\hline \multirow[t]{2}{*}{ Shenmu } & Hongliulin & $\begin{array}{l}\text { ZY18800/33/72 } \\
\text { SL1000, SGZ1400/ } \\
\quad 3 \times 1500\end{array}$ & Shearers are imported & $305,2,900 \mathrm{~m}, 12 \mathrm{Mt} /$ year \\
\hline & Ningtiaota & ZY12000/29/65 & All Chinese-made & \\
\hline \multirow[t]{5}{*}{ Others } & Dongpang & ZY10800/30/65D & All Chinese-made & $210,1,660 \mathrm{~m}$ \\
\hline & Xiegou & ZY12000/28/64D & All Chinese-made & \\
\hline & Xutong & ZY11000/28/63D & All Chinese-made & \\
\hline & Dalong & ZY10000/25/56 & All Chinese-made & \\
\hline & Liangbei & ZY6000/25/50 & All Chinese-made & $150,1200 \mathrm{~m}, 150 \mathrm{kt} / \mathrm{m}$ \\
\hline
\end{tabular}

output of $10 \mathrm{kt}$ were achieved at a face shear height of $4.8 \mathrm{~m}$ under safe and efficient production conditions, establishing world records in terms of shear height, dip angle, and production efficiency of the FMM/fully mechanized top coal caving faces.

\section{Fully mechanized top coal caving technology and equipment for ultra-thick seams}

Top coal caving mining method was originated in Europe, and rarely applied in coal mines worldwide. However, this mining method has good adaptability in thick-seams in Chinese coal mines. It has been successfully applied in high-methane, spontaneously inflammable thick seams; thick seams with large dip angles; unconsolidated and unstable thick seams; complex structure seams; and 4-5 m thick seams, as well as the residual mining of thick seams. Nearly 30 years of mining practices have demonstrated that fully mechanized top coal caving mining is safe, lowconsumption coal mining technology that assures high productivity and high efficiency. It has become an important technical means for establishing high-productivity high-efficiency mines in thick seam mine areas and plays a critical role in Chinese coal industry (Table 3 ).
5.1 Fully mechanized top coal caving technology with large shear height for ultra-thick seams of $14-20 \mathrm{~m}$

Based on then-current status of the fully mechanized top coal caving technology, Mao and Kang (2003) proposed the fully mechanized top coal caving method with large shear height for thick seams in 2003 through the analysis on influential factors to further enhance productivity of coal faces, which considered both the advantages of the FMM with large shear height and top coal caving. This method has become the main approach to mining full-seam of ultra-thick seams of 14-20 m, and it is also an important means for achieving output of $10 \mathrm{Mt} /$ year from a fully mechanized top coal caving face.

During Chinese 11th five-year plan period, National Science and Technology Support Program known as "Research and development of packaged fully mechanized top coal caving mining technology and equipment with large shear height for ultra-thick seams", successfully developed the complete sets of fully mechanized top coal caving mining technology and equipment with large shear height and a face output of $10 \mathrm{Mt} /$ year. The fully mechanized caving hydraulic supports ZF15000/28/52 with four legs, high shear height were developed for the aforementioned top coal 
Table 3 List of fully mechanized top coal caving teams with annual output exceeding 3 million tons in 2011, China

\begin{tabular}{|c|c|c|c|c|c|c|c|}
\hline No. & Mining team name & $\begin{array}{l}\text { Seam } \\
\text { thickness } \\
\text { (m) }\end{array}$ & $\begin{array}{l}\text { Annual } \\
\text { output } \\
\text { (kt) }\end{array}$ & No. & Mining team name & $\begin{array}{l}\text { Seam } \\
\text { thickness } \\
\text { (m) }\end{array}$ & $\begin{array}{l}\text { Annual } \\
\text { output } \\
(\mathrm{kt})\end{array}$ \\
\hline 1 & $\begin{array}{l}\text { FMM Team 1, Underground No.2 mine, } \\
\text { Pingshuo }\end{array}$ & 12.60 & $9,562.6$ & 11 & $\begin{array}{l}\text { FMM Team, Underground Mine No.3 } \\
\text { Pingshuo }\end{array}$ & 10.25 & $5,500.8$ \\
\hline 2 & $\begin{array}{l}\text { FMM Team, Underground No.1 mine, } \\
\text { Pingshuo }\end{array}$ & 10.50 & 9,316 & 12 & FMM Team, Lingdong Mine, Jalainur & 14.30 & $4,687.4$ \\
\hline 3 & FMM Team 1, Tashan Mine, Datong & 14.50 & $7,288.3$ & 13 & FMM Team 1, Daliuta Mine, Shendong & 6.90 & 4,658 \\
\hline 4 & FMM Team 2, Tashan Mine, Datong & 12.29 & $7,211.7$ & 14 & FMM Team, Baodian Mine, Yankuang & 7.12 & $4,160.8$ \\
\hline 5 & Mining Team 1, Suancigou Mine, Yitai & 11.09 & $7,064.9$ & 15 & $\begin{array}{l}\text { FMM Team 2, Jining No.3 Mine, } \\
\text { Yankuang }\end{array}$ & 7.33 & $4,004.9$ \\
\hline 6 & FMM District, Dongtan Mine, Yankuang & 9.50 & 6,304 & 16 & FMC Team, Daping Mine, Tiefa & 11.30 & 3,902 \\
\hline 7 & $\begin{array}{l}\text { FMM Team 1, Xinglongzhuang Mine, } \\
\text { Yankuang }\end{array}$ & 8.78 & $6,100.5$ & 17 & FMM Team, Zhangcun Mine, Luan & 6.08 & 3,782 \\
\hline 8 & FMM Team, Changcun Mine, Luan & 6.30 & $5,701.7$ & 18 & FMM Team 1, Wangzhuang Mine, Luan & 6.81 & $5,517.3$ \\
\hline 9 & FMM Team 1, Baode Mine, Shenhua & 7.00 & $5,607.1$ & 19 & $\begin{array}{l}\text { FMM Team 3, Zaoquan Mine, Ningxia } \\
\text { Coal }\end{array}$ & 7.95 & $3,194.4$ \\
\hline 10 & FMC District, Xinjulong mine, Xinwen & 8.10 & 5,597 & & & & \\
\hline
\end{tabular}

caving mining of 14-20 m ultra-thick seams, which increased the shear height of working faces to $5 \mathrm{~m}$ with mined full-seam thickness up to $20 \mathrm{~m}$. This system underwent an industrial test on working face 8105 in the Tashan Mine of the Datong coal mining district, and the annual output of this face reached 10.85 million tons. The main research achievements are as follows:

(1) The overall matching pattern for the parallel and balanced shear and caving in coal face and complete sets of technical system for the fully mechanized top coal caving mining used to extract ultra-thick seams with shear height of $5 \mathrm{~m}$ or more; the invention of a three-dimensional (3D) dynamic optimized design method for coupling hydraulic supports with surrounding rock; the innovation of the world first fully mechanized top coal caving hydraulic supports with working resistance of $15,000 \mathrm{kN}$ and maximum height of $5.2 \mathrm{~m}$ (Fig. 2); the creation of a novel frame-type structure for the top coal caving hydraulic supports with large shear height, including the stability mechanism with two front linking bars and two rear linking bars, a walkway set between linking bars, and a coal caving mechanism with a strongly waving tail beam and inserter plate; the achievement of balanced production between shear and caving in the top coal caving face using large shear height in 14-20 m ultra-thick seams with an annual output of $10 \mathrm{Mt} /$ year; the development of novel transitional hydraulic supports and the hydraulic supports used in face ends allowing for top coal caving in the transitional sections.
(2) Development of the MG750/1915-GWD shearer, the DSJ140/350/3 $\times 500$ entry belt conveyor with large capacity and long distance, the SGZ1200/2 × 1,000 rear scraper conveyor, a $55 \mathrm{t}$ support carrier, and key equipment for the working face power supply. The achievement of all homemade packaged equipment for fully mechanized top coal caving faces with large shear height used in ultra-thick seams, and the improvement of compatibility, adaptability, and reliability of this packaged equipment. The packaged equipment used in face 8105 in the Tashan Mine, the demonstrated fully mechanized top coal caving face was list on Table 4.

(3) Projection of a technical standard system for the fully mechanized top coal caving mining with large shear height, establishment and updating of relevant technical standards and specifications, definition of relevant testing methods, and development of relevant testing devices.

Thus far, a fully mechanized top coal caving face armed entirely with homemade equipment can yield an annual output of 6-10 Mt. The full mechanized top coal caving technology with large shear height exhibits the broad potential for more extensive application in the mining of coal seams with similar conditions home and abroad.

5.2 Fully mechanized top coal caving technology with large shear height for soft thick seams with large dip angles

With regard to the technical problems related to equipment antitoppling, antislip and enhancing coal recovery rates for 


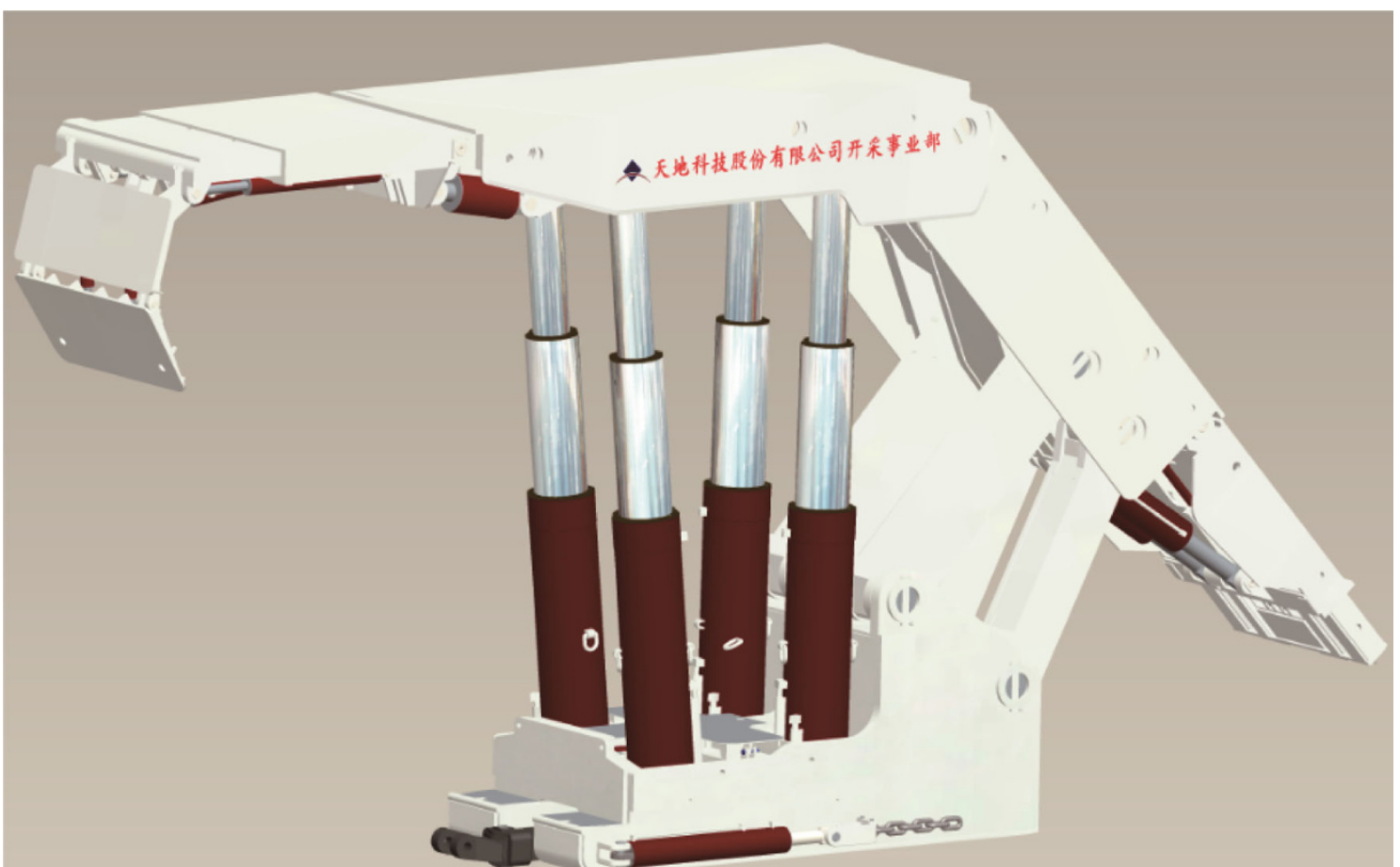

Fig. 2 Structure of ZF15000/28/52 top coal caving support

Table 4 Packaged equipment for face 8105 of fully mechanized top coal caving in Tashan Mine

\begin{tabular}{|c|c|c|c|c|}
\hline No. & Name & Model & $\begin{array}{l}\text { Power } \\
(\mathrm{kW})\end{array}$ & Capacity \\
\hline 1 & Hydraulic support & ZF15000/28/52 & & $15,000 \mathrm{kN}$ \\
\hline 2 & Coal shearer & $\begin{array}{l}\text { MG750/1915- } \\
\text { GWD }\end{array}$ & 1,915 & $2,000 \mathrm{t} / \mathrm{h}$ \\
\hline 3 & $\begin{array}{l}\text { Front scrapper } \\
\text { conveyor }\end{array}$ & SGZ1000/1710 & $2 \times 855$ & $2,500 \mathrm{t} / \mathrm{h}$ \\
\hline 4 & $\begin{array}{l}\text { Rear scrapper } \\
\text { conveyor }\end{array}$ & SGZ1200/2000 & $2 \times 1,000$ & $3,000 \mathrm{t} / \mathrm{h}$ \\
\hline 5 & Transfer conveyor & PF6/1542 & 450 & $3,500 \mathrm{t} / \mathrm{h}$ \\
\hline 6 & Crusher & SK1118 & 400 & $4,250 \mathrm{t} / \mathrm{h}$ \\
\hline 7 & Belt conveyor & $\begin{array}{c}\text { DSJ140/350/ } \\
3 \times 500\end{array}$ & $3 \times 500$ & $3,500 \mathrm{t} / \mathrm{h}$ \\
\hline 8 & Emulsion pump & BRW400/31.5 & 250 & $400 \mathrm{~L}$ \\
\hline 9 & Spray pump & BRW500/12.5 & 132 & $500 \mathrm{~L}$ \\
\hline
\end{tabular}

the fully mechanized top coal caving mining technique used in soft and thick seams with large dip angles and large shear height, a complete package of security techniques were produced that ranged from hydraulic support structures, working face layout, and top coal caving processes to working face management. These measures included: (1) three hydraulic supports in the face end consisted of an anchoring station to guarantee longitudinal stability of the working face supports; (2) the hydraulic supports were

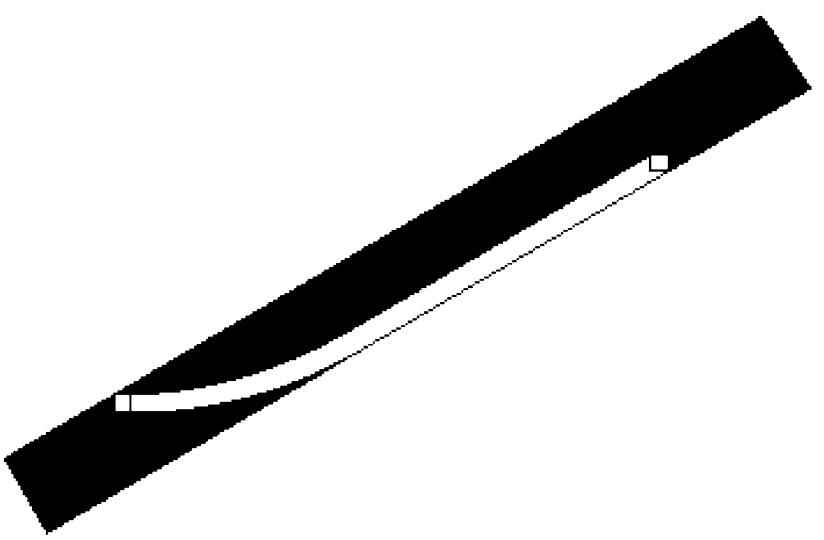

Fig. 3 The inclined-arc transition-horizontal layout of the working face

equipped with robust and removable lateral guard plates adjustable from both sides, and base adjustors attached to them; (3) the working face was arranged in an "inclinedarc transition-horizontal" pattern (Fig. 3) to minimize the grade on the lower working face end and to guarantee the stability of hydraulic supports there; (4) the mining pattern, "unidirectional shearing, two-shearing and one top coal caving" was adopted to restrain the hydraulic supports from slippage on the basis of the optimization of the top coal caving process; (5) along the inclination of the working face, top coal is caved from upper to low part in the upper of the face to maintain support stability, and in other sections of the face, top coal is caved from low to 
upper part to ensure greater top coal recovery (Huang et al. 2010; Sun and Lou 2011).

In the case of the Gushan Mine, the Pingzhuang coal mining district of Inner Mongolia, the average thickness of seam $6-2$ was $7.5 \mathrm{~m}$; the dip angle was $28^{\circ}-41^{\circ}$, and the hardness coefficient was $0.92-1.03$. This seam showed various degrees of contact metamorphism. As a result, part of the seam was believed to be unrecoverable. However, guaranteed by the aforementioned key technology and technological research, the safe and efficient mining was achieved under such complex conditions. Industrial tests indicated that the equipment was pretty stable in the fully mechanized top coal caving faces, and top coal recovery was as high as $80 \%$. This example was a typical fully mechanized top coal caving face of large dip angle with safety and high efficiency, which is a good reference for the equipment antitoppling and antislip in fully mechanized top coal caving faces under similar conditions.

The representative mining examples of the fully mechanized top coal caving faces for the thick seams with large dip angles are listed on Table 5.

\section{Backfilling mining technology and equipment}

In addition to facilitating economic development, the coal industry must resolve a series of environmental problems caused by underground mining. It is apparent that the biggest victims of coal mining are the ground environment and underground water systems. To resolve the resource and environmental problems caused by mass coal exploitation and to ensure virtuous circulation of coal mining and surface eco-protection, backfilling mining technology has undergone sustained technical progress in China during the past several years. China Coal Technology \& Engineering Group Corp., China University of Mining \& Technology, and Jizhong Energy Resources developed three sets of backfilling mining methods and equipment by using gangues, pastes, and high-water materials, respectively, as well as a fully proprietary integrated mechanized backfilling and mining technology package (Feng 2009; Hu 2012; Miao 2012; Liu 2013). The fully mechanized integrated solid backfilling and mining hydraulic support is shown as Fig. 4. Numerous key technical breakthroughs have been

Table 5 Mining cases of fully mechanized top coal caving faces on thick seams with large dip angles

\begin{tabular}{|c|c|c|c|c|c|}
\hline Mine name (working face) & Wulan mine (5335) & Wangjiashan (44407) & Xinji No.1 Mine & Gushan-3 well & Huafeng (1410) \\
\hline Buried depth (m) & 350 & $260-320$ & $450-480$ & 350 & $960-1,040$ \\
\hline Seam thickness (m) & 8 & $13.5-23$ & $6-8$ & 7.5 & $5.6-6.9$ \\
\hline Dip angle $\left(^{\circ}\right)$ & $25-35$ & $38-49$ & $25-35$ & $28-41$ & $30-34$ \\
\hline Seam hardness & $0.6-1.2$ & 1.0 & $0.9-1.2$ & $0.92-1.03$ & 1.08 \\
\hline Cutting height (m) & & 2.6 & 2.5 & 2.6 & 2.4 \\
\hline Monthly output (kt) & $70-80$ & 53 & 150 & 100 & 52 \\
\hline Face length (m) & 110 & 115 & & 78 & 142 \\
\hline
\end{tabular}

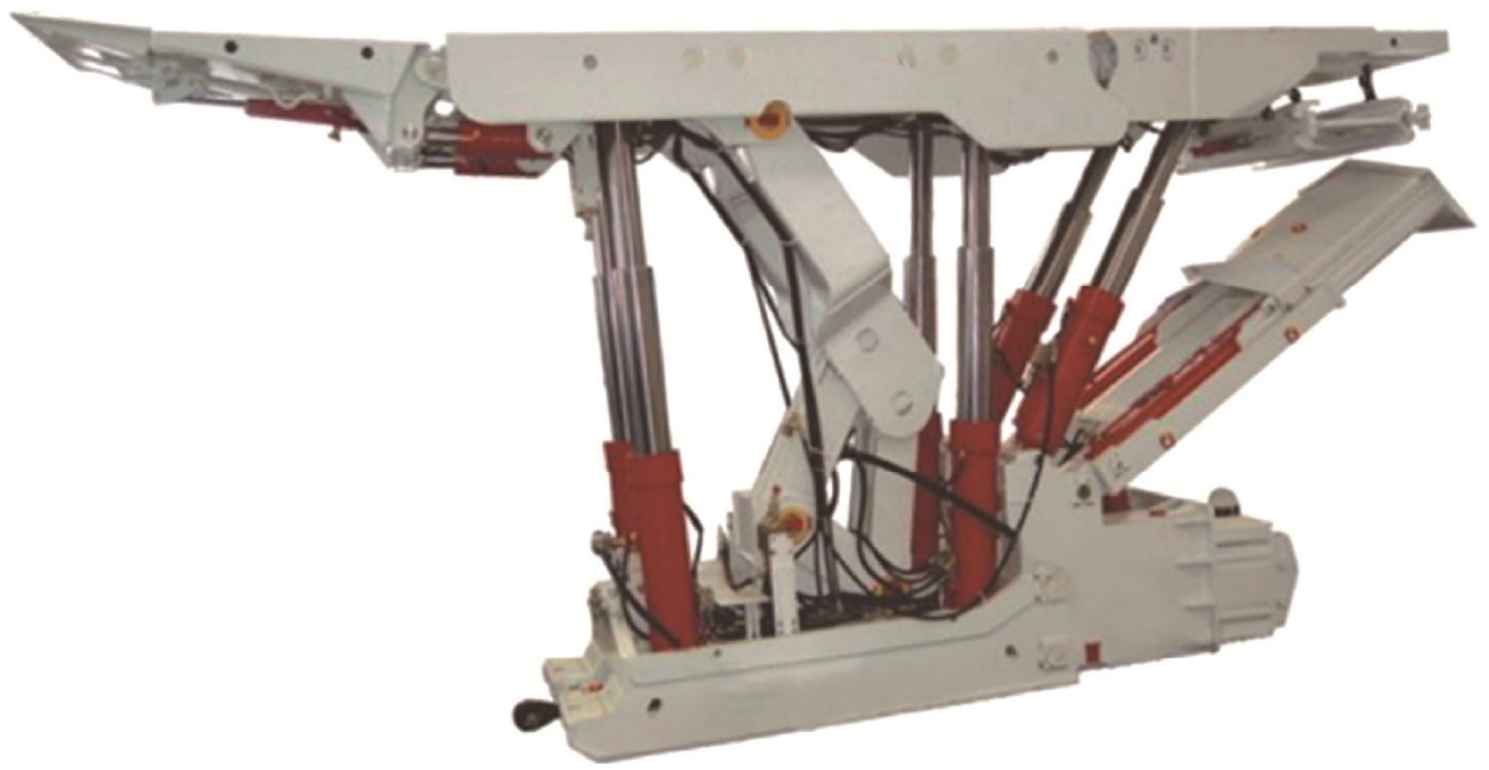

Fig. 4 Fully mechanized integrated solid backfilling and mining hydraulic support 
reported with respect to backfilling mining technology and equipment, and mass industrial-scale application has been implemented in approximately 20 mine areas under large urban construction groups, railway and highway cross network, and large marine bodies and unconsolidated aquifers with remarkable economic, social, and environmental performances.

\section{Problems and prospect}

China is currently on international advanced level in key technologies for top hydraulic supports and heavy-duty conveyor equipment, and the global leader in the fully mechanized top coal caving mining technology and equipment. Hydraulic supports for the FMM and its electro-hydraulic control systems are China-made, and packaged FMM technology and equipment produced by China have been exported to other countries.

However, the following problems persist calling for immediate resolution before full mechanization of coal production can be realized:

(1) Technical problems of the FMM in complex difficult seams. The seams difficultly extracted under varying complex geological conditions are the main challenges for the extensive application of the FMM technology. The packaged FMM equipment for large dip angle, steeply inclined, and other complex difficult seams are critical for facilitating the safe and efficient automatic mining of these seams.

(2) Fully mechanized reconstruction and higher resource recovery technology for minor coal mines. In contrast to the modern large coal mines with output of $10 \mathrm{Mt}$, safety, high efficiency and high recovery rate representing international leading levels, minor coal mines also exist that lag behind in terms of mining methods, technology, and equipment. Many minor coal mines still employ outdated mining technology and equipment, resulting in low efficiency, high safety risk, and low resource recovery rate. Further researches targeting these conditions are needed for developing technology and equipment suitable for the fully mechanized reconstruction of minor coal mines to enable safe, efficient, high recovery production of these mines.

(3) Research and development of packaged intelligent technology and equipment for coal mining, which should focus on key equipment such as intelligent control high-speed electric haulage shearers, in addition to the development of working face central control systems compatible with the production technology and improvement of full automation of fully mechanized work faces.

Open Access This article is distributed under the terms of the Creative Commons Attribution License which permits any use, distribution, and reproduction in any medium, provided the original author(s) and the source are credited.

\section{References}

Fan YC (2012) Some mining methods for steep inclined difficult seams. National technical symposium of coal mines on the mining of complex difficult seams, Chengdu, pp 66-68

Feng GM (2009) Research on the superhigh-water packing material and filling mining technology and their application. Doctor's thesis, China University of Mining \& Technology, Xuzhou

Hu BN (2012) Backfill mining technology and development tendency in China coal mine. Coal Sci Technol 40(11):1-5

Huang ZZ, Ren YF, Zhang HJ (2010) Study on key technology of fully mechanized top coal caving in extra-thick soft coal seam with great dip angle. J China Coal Soc 35(11):1878-1882

Liu JG (2013) Application and study on backfill mining technology and equipment in deep mine with depth over $1000 \mathrm{~m}$. Coal Sci Technol 41(9):1-5

Mao DB, Kang LJ (2003) High cutting fully-mechanized mining and application feasibility. Coal Min Technol 8(1):11-14

Mao DB, Lan H, Xu G (2011) Thin coal-seam mechanized mining status and new development of China. Min Technol 16(3):11-14

Miao XX (2012) Progress of fully mechanized mining with solid backfilling technology. J China Coal Soc 37(8):1247-1255

Ning Y (2011) Innovating safe and high-efficiency coal mining technology and supporting extra-large mine construction. Coal Min Technol 16(3):1-3

Ning Y (2012) Fully-mechanized high cutting mining technology and equipment in China. China Coal Industry Publishing House, Beijing

Ning Y (2013) Current status and thinking of full-mechanized mining technology in Chinese coal mines. Coal Min Technol 18(1):1-3

Sun ZG, Lou JF (2011) Anti-sliding and anti-toppling technology of top-coal caving powered support for extremely-thick coal-seam with large angle. Coal Min Technol 16(6):39-40

Wang A (2005) Production technology of modern 100 million ton mine areas. China Coal Industry Publishing House, Beijing

Wang JH (2006) Present status and development tendency of fully mechanized coal mining technology and equipment with high cutting height in China. Coal Sci Technol 34(1):4-7

Wang GF (2009) Development and application of completed set equipment for effective mining of thin seams. Coal Sci Technol 9(37):86-89

Wang JH (2011) Present status and prospects of modernized mining technology and equipment in China coal mine. Coal Sci Technol 39(1):1-3 